\title{
Implementing SVPWM technique to Axial Flux Permanent Magnet Synchronous Motor Drive with Internal Model Current Controller
}

\author{
Araz Darba ${ }^{1}$ \\ Mohammad Esmalifalak ${ }^{1}$ \\ Ebrahim Sarbaz Barazandeh ${ }^{2}$ \\ ${ }^{1}$ Islamic Azad University Ardabil Branch \\ Ardebil Iran \\ ${ }^{2}$ Islamic Azad University, Kahnooj Branch
}

\begin{abstract}
This paper presents a study of axial flux permanent magnet synchronous motor (AFPMSM) drive system. An internal model control (IMC) strategy is introduced to control the AFPMSM drive through currents, leading to an extension of PI control with integrators added in the off-diagonal elements to remove the cross-coupling effects between the applied voltages and stator currents in a feed-forward manner. The reference voltage is applied through a space vector pulse width modulation (SVPWM) unit. A diverse set of test scenarios has been realized to comparatively evaluate the state estimation of the sensor-less AFPMSM drive performances under the implemented IMCbased control regime using a SVPWM inverter. The resulting MATLAB simulation outcomes in the face of no-load, nominal load and speed reversal clearly illustrate the well-behaved performances of IMC controller and SVPWM technique to an Axial Flux PM Motor Drive system.
\end{abstract}

\section{INTRODUCTION}

In recent years, a great deal of interest has been dedicated to develop digital control techniques to industrial AC drive systems and variable speed drives. State vector pulse-width modulation (SVPWM) presents one of the most efficient methods for this purpose which relies on analysis of threephase inverter in the complex plane by the Space Vector theory. SVPWM controls the motor based on the switching of the space voltage vectors by which an approximate circular rotary magnetic field is obtained. Compared to the conventional sinusoidal pulse width modulation (SPWM), SVPWM is more suitable for digital implementation and can increase the obtainable maximum output voltage with maximum line voltage. Moreover, it can obtain a better voltage total harmonic distortion factor. The SPWM main goal is to achieve symmetrical 3-phase sine voltage waveforms of adjustable voltage and frequency, while SVPWM takes the inverter and motor as a whole, using the eight fundamental voltage vectors, to realize variable frequency of voltage and speed adjustment.[1]-[5]

In recent years, paramagnet magnet $(\mathrm{PM})$ machines have gained more popularity than induction motors in some fields of AC variable speed drives due to the availability of new PM materials that can introduce more energy and field. These machines lack any windings in the rotors and hence do not produce rotor loss, leading to more efficiency than induction motor drives.

PM machines are often classified into two groups: brushless DC (BLDC) and permanent magnet synchronous motor (PMSM). In BLDC machines, back-EMF is trapezoidal and hence they are prone to produce more harmonics and losses especially in high speeds in contrast to PMSM machines due to the sinusoidal back-EMF [6].

First electrical machines are Axial Flux and their excitation system was magnetic (M. Faraday 1831). In recent years Axial flux machines because of two significant features are more considered: high moment of inertia and low speed. Both of these properties are due to impact structure and high diagonal size. High moment of inertia plays the flywheel role and so rotor speed remains stable. And low speeds are available because of high diagonal size and rotor can hold more polepairs, this feature is more interesting in tensional and lifting application. And mechanical gear box is needed no more and this reduces cost and increases efficiency of system [7], [8].

\section{MOTOR MODEL}

The stator windings of Axial Flux Permanent Magnet motor is different from radial flux PMSMs but we can use conventional PMSM model for Axial Flux PMSMs and the difference is in stator parameters like calculation of inductances but we don't need these because we can obtain parameters by measurement. In addition there is no difference between the Back-EMF produced by a permanent magnet and that produced by an excited coil [9]. Hence the mathematical model of an Axial Flux Permanent Magnet Synchronous Motor is similar to that of the radial PMSM. The following assumptions are made in the derivation:

1) Saturation is neglected although it can be taken into account by parameter changes

2) The Back-EMF is sinusoidal 
3) Eddy currents and Hysteresis and stray losses are negligible

With these assumptions the stator $\mathrm{d}, \mathrm{q}$ equations in the rotor reference frame are [6]:

$$
\begin{aligned}
& v_{d}=R i_{d}+p \lambda_{d}-\omega_{s} \lambda_{q} \\
& v_{q}=R i_{q}+p \lambda_{q}-\omega_{s} \lambda_{d}
\end{aligned}
$$

Where

$$
\begin{gathered}
\lambda_{q}=L_{q} i_{q} \\
\lambda_{d}=L_{d} i_{d}+\lambda_{a f}
\end{gathered}
$$

$v_{d}$ and $v_{q}$ are the $d, q$ axis voltages, $i_{d}$ and $i_{q}$ are the $d, q$ axis stator currents, $L_{d}$ and $L_{q}$ are the $d, q$ axis inductances, $\lambda_{d}$ and $\lambda_{q}$ are the $d, q$ axis stator flux linkages, while $R$ and $\omega_{s}$ are the stator resistance and inverter frequency, respectively. $\lambda_{a f}$ is the flux linkage due to the rotor magnets linking the stator.

The electric torque is:

$$
T_{e}=3 P\left[\lambda_{a f} i_{q}+\left(L_{d}-L_{q}\right) i_{d} i_{q}\right] / 2
$$

And the equation for motor dynamic is:

$$
T_{e}=T_{l}+B \omega_{r}+J P \omega_{r}
$$

$P$ is the number of pole-pairs, $T_{l}$ is the load torque, $B$ is the damping coefficient, $\omega_{r}$ is the rotor speed, and $J$ is the moment of inertia. The inverter frequency is related to the rotor speed as follows:

$$
\omega_{s}=P \omega_{r}
$$

The machine model is nonlinear as it contains product terms such as speed with $i_{d}$ and $i_{q}$.

For dynamic simulation, the equations of the PMSM presented in (1)-(6) must be expressed in state-space form as shown in (8)-(10):

$$
\begin{gathered}
P \omega_{r}=\left(T_{e}-T_{l}-B \omega_{r}\right) / J \\
P i_{d}=\left(v_{d}-R i_{d}+\omega_{s} L_{q} i_{q}\right) / L_{d} \\
P i_{q}=\left(q-R i_{q}-\omega_{s} L_{d} i_{d}-\omega_{s} \lambda_{a f}\right) / L_{q}
\end{gathered}
$$

The $d, q$ variables are obtained from $a, b, c$ variables through the Park transform defined below:

$$
\left[\begin{array}{l}
v_{d} \\
v_{q} \\
v_{o}
\end{array}\right]=\left[\begin{array}{ccc}
\cos (\theta) & \cos (\theta-2 \pi / 3) & \cos (\theta+2 \pi / 3) \\
\sin (\theta) & \sin (\theta-2 \pi / 3) & \sin (\theta+2 \pi / 3) \\
1 / 2 & 1 / 2 & 1 / 2
\end{array}\right] \cdot\left[\begin{array}{c}
v_{a} \\
v_{b} \\
v_{c}
\end{array}\right]
$$

The $a, b, c$ variables are obtained from the $d, q$ variables through the inverse of the Park transform defined below:

$$
\left[\begin{array}{l}
v_{a} \\
v_{b} \\
v_{c}
\end{array}\right]=\left[\begin{array}{ccc}
\cos (\theta) & \sin (\theta) & 1 \\
\cos (\theta-2 \pi / 3) & \sin (\theta-2 \pi / 3) & 1 \\
\cos (\theta+2 \pi / 3) & \sin (\theta+2 \pi / 3) & 1
\end{array}\right] \cdot\left[\begin{array}{c}
v_{d} \\
v_{q} \\
v_{o}
\end{array}\right]
$$

\section{SVPWM}

\section{A. Principles of SVM}

Space vector modulation (SVM) is one of the preferred realtime modulation techniques and is widely used for digital control of voltage source inverters [10], [11]. This section presents the principle and implementation of the space vector modulation for the two-level inverter.

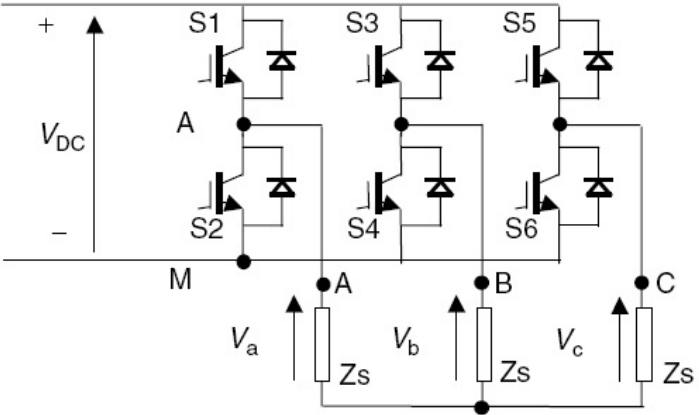

Figure 1. Three phase, two level inverter

TABLE I

Space Vectors, Switching States and On State Switches

\begin{tabular}{c|c|c|c}
\hline \hline $\begin{array}{c}\text { Space } \\
\text { Vector }\end{array}$ & $\begin{array}{c}\text { Switching } \\
\text { States }\end{array}$ & $\begin{array}{c}\text { On State } \\
\text { Switches }\end{array}$ & Vector Definition \\
\hline \hline$\vec{V}_{0}$ & {$[\mathrm{PPP}]$} & $S_{1}, S_{3}, S_{5}$ & $\vec{V}_{0}=0$ \\
& {$[\mathrm{OOO}]$} & $S_{4}, S_{6}, S_{2}$ & $\vec{V}_{1}=\sqrt{2}\left(\sqrt{2} V_{d c}+\right.$ \\
$\vec{V}_{1}$ & {$[\mathrm{POO}]$} & $S_{1}, S_{6}, S_{2}$ & $\left.\sqrt{3} V_{\alpha}+V_{\beta}\right) / 4 V_{d c}$ \\
$\vec{V}_{2}$ & {$[\mathrm{PPO}]$} & $S_{1}, S_{3}, S_{2}$ & $\vec{V}_{2}=\left(V_{d c}+\sqrt{6} V_{\alpha}\right) / 2 V_{d c}$ \\
$\vec{V}_{3}=\sqrt{2}\left(\sqrt{2} V_{d c}+\right.$ \\
$\vec{V}_{3}$ & {$[\mathrm{OPO}]$} & $S_{4}, S_{3}, S_{2}$ & $\left.\sqrt{3} V_{\alpha}-V_{\beta}\right) / 4 V_{d c}$ \\
& & & $\vec{V}_{4}=\sqrt{2}\left(\sqrt{2} V_{d c}+\right.$ \\
$\vec{V}_{4}$ & {$[\mathrm{OPP}]$} & $S_{4}, S_{3}, S_{5}$ & $\left.\sqrt{3} V_{\alpha}+V_{\beta}\right) / 4 V_{d c}$ \\
$\vec{V}_{5}$ & {$[\mathrm{OOP}]$} & $S_{4}, S_{6}, S_{5}$ & $\vec{V}_{5}=\left(V_{d c}+\sqrt{6} V_{\alpha}\right) / 2 V_{d c}$ \\
$\vec{V}_{6}$ & {$[\mathrm{POP}]$} & $S_{1}, S_{6}, S_{5}$ & $\vec{V}_{6}=\sqrt{2}\left(\sqrt{2} V_{d c}+\right.$ \\
$\left.\sqrt{3}_{\alpha}-V_{\beta}\right) / 4 V_{d c}$ \\
\hline
\end{tabular}

The operating status of the switches in the two-level inverter in Fig. 1 can be represented by switching states. The switching state ' $\mathrm{P}$ ' denotes that the upper switch in an inverter leg is on and the inverter terminal voltage $\left(V_{A N}, V_{B N}, V_{C N}\right)$ is positive $\left(+V_{d c}\right)$ while ' $\mathrm{O}$ ' indicates that the inverter terminal voltage is zero due to the conduction of the lower switch. There are eight possible combinations of switching states in the two-level inverter as listed in Table 1. The switching state [POO], for example, corresponds to the conduction of $S 1, S 6$, and $S 2$ in the inverter legs $A, B$, and $C$, respectively. Among the eight switching states, $[\mathrm{PPP}]$ and $[\mathrm{OOO}]$ are zero states and the others are active states.

The active and zero switching states can be represented by active and zero space vectors, respectively. A typical space vector diagram for the two-level inverter is shown in Fig. 2, where the six active vectors $\vec{V}_{1}$ to $\vec{V}_{6}$ form a regular hexagon with six equal sectors (I to VI). The zero vector $\vec{V}_{0}$ lies on the center of the hexagon.

\section{B. Simulation of SVPWM}

Based on the principles of SVPWM, the simulation models for generating SVPWM waveforms mainly include the sector selection, gate switching time calculation, generation of SVPWM waveforms. 


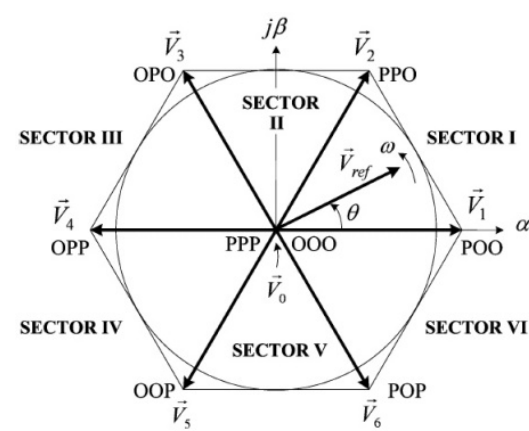

Figure 2. Diagram of voltage space vector

TABLE II

SECTOR SELECTION RULE

\begin{tabular}{l|c}
\hline \hline \multicolumn{1}{c|}{ Angle } & Sector \\
\hline \hline From 0 to 60 & 1 \\
From 60 to 120 & 2 \\
From 120 to 180 & 3 \\
From -180 to -120 & 4 \\
From -120 to -60 & 5 \\
From -60 to 0 & 6 \\
\hline
\end{tabular}

At the first, it is necessary to determine that the current voltage vector is within which sector. Considering that the expression of vector in the $\alpha-\beta$ coordinate system is suitable for controlling implementation, the angle can be determined in a fuzzy manner from $\alpha-\beta$ form of voltage vector. And for doing this and considering speed reversal action the atan2 function is proposed. The atan 2 function provides angle in radians that must be converted to degree. Sector selection is implemented considering Table 2.

In the next step gate switching time is calculated. For each of three phases after getting number of selected sector one of the equations introduced in Table I is used. Gate on and off time is calculated as follows.

$$
\begin{gathered}
T_{\text {ON }}=(1-V) / 2 \\
T_{\text {OFF }}=(1+V) / 2
\end{gathered}
$$

$V$ is the specified voltage vector from Table I according to the selected sector.

For generating logic gate command a ramp signal is generated and then compared with gate switching times of each phase and gate commands of inverter's switches are generated considering Table III.

\section{CURRENT CONTROLLER}

\section{A. Internal Model Control}

In this paper, the internal model control (IMC) method [11] is introduced and applied to ac machine current control. A permanent magnet synchronous machine (PMSM) is the working example. The main benefits of IMC are:

1) Synchronous-frame PI or PI-type current controllers are obtained.

2) The controller parameters (gain and integration time) are expressed directly in certain machine parameters and the desired closed-loop bandwidth. This simplifies the design procedure and trial-and-error steps are avoided.

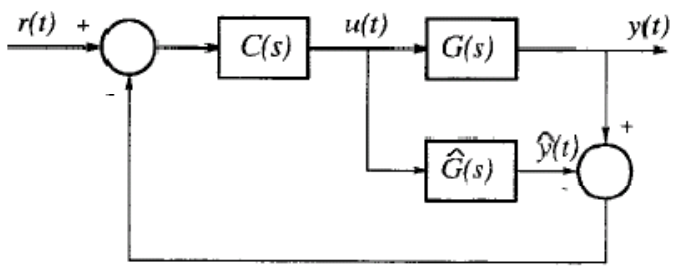

Figure 3. IMC structure

TABLE III

\begin{tabular}{|c|c|c|c|c|c|}
\hline \multicolumn{2}{|c|}{ Phase A } & \multicolumn{2}{|c|}{ Phase B } & \multicolumn{2}{|c|}{ Phase C } \\
\hline \multicolumn{2}{|c|}{$T_{O F F} \leq R \leq T_{O N}$} & \multicolumn{2}{|c|}{$\begin{array}{c}\text { If } \\
T_{O F F} \leq R \leq T_{O N}\end{array}$} & \multicolumn{2}{|c|}{$\begin{array}{c}\text { If } \\
T_{O F F} \leq R \leq T_{O N}\end{array}$} \\
\hline & Switch & & & & Switch \\
\hline & 20 & & & 1 & 6 \\
\hline \multicolumn{2}{|c|}{ Else } & & \\
\hline $1 \mathrm{OH}$ & $\begin{array}{r}\text { Swi } \\
2 \mathrm{O} \\
\end{array}$ & 30 & & & \\
\hline
\end{tabular}

GATE COMMAND Signal GeNERATION

IMC was originally developed for chemical engineering applications [7] and is considered as a robust control method. Before applying IMC to the current control problem, a general presentation of the method is given. The IMC structure is depicted in Fig. 3. The structure uses an internal model $\widehat{G}(s)$ in parallel with the controlled system (plant) $G(s)$. For an ac machine, and are, thus, the stator voltage and current vectors, respectively, while $r=\left[\begin{array}{ll}i_{d}^{r e f} & i_{q}^{r e f}\end{array}\right]^{T}$ is the current set-point (reference) vector. The control loop is augmented by a block $C(s)$; the so-called IMC controller. $G(s), \widehat{G}(s)$ and $C(s)$ are all transfer function matrices.

\section{B. Controller Design for the PMSM}

Since $G(s)$ has no right-half-plane zeros and behaves as a first-order system for high frequencies, we can let

$$
G(s)=G^{-1}(s) L(s)
$$

where all diagonal elements may be selected equal,

$$
L(s)=(\alpha I) /(s+\alpha)
$$

Herein lies the main benefit of using IMC. The tuning problem, which for a PI controller involves adjustment of two parameters, is reduced to the selection of one parameter only, the desired closed-loop bandwidth. Since, for a first-order system, the $10 \%-90 \%$ rise time $t_{r}$ is related to $\alpha$ as $t_{r}=$ $\ln 9 / \alpha$, a specification of the rise time immediately yields the desired bandwidth and, in turn, a suitable controller. we find that the equivalent classic controller becomes:

$$
F(s)=\alpha\left[\begin{array}{cc}
L_{d}\left(1+\frac{R_{s}}{s L_{d}}\right) & -\frac{\omega_{r} L_{q}}{s} \\
\frac{\omega_{r} L_{q}}{s} & L_{q}\left(1+\frac{R_{s}}{s L_{q}}\right)
\end{array}\right]
$$




$$
F_{P I}(s)=\left[\begin{array}{cc}
K_{d}\left(1+\frac{1}{s T_{i d}}\right) & 0 \\
0 & K_{q}\left(1+\frac{1}{s T_{i q}}\right)
\end{array}\right]
$$

It is, thus, more straightforward to implement the classic structure than the IMC structure Fig. 3. A comparison with two standard PI controllers (each one for the $d$ and $q$ loops) shows that (17) is an extension of PI control with integrators added in the anti-diagonal elements of $F(s)$ in order to remove the cross coupling, with

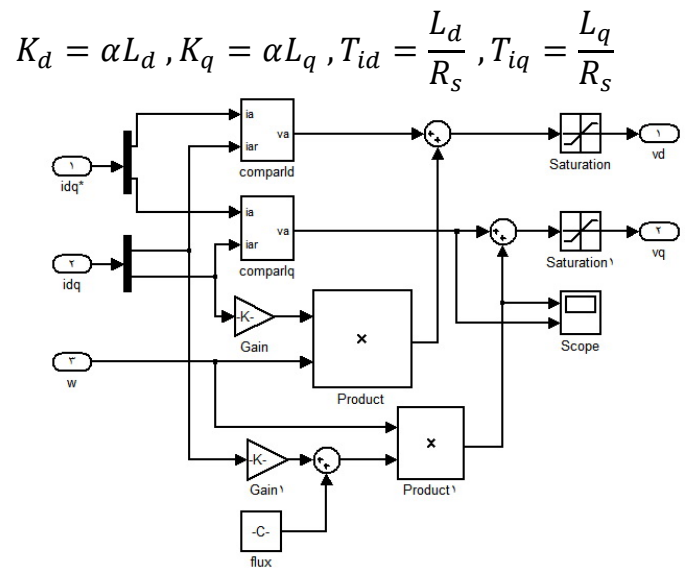

Figure 4: Current controller block

Figure 4 shows the schematic diagram of the current controller represented using SI blocks. Two PI controllers are employed to regulate the stator current and feed-forward control is used to decouple the dynamics between the applied voltages and the currents. The inputs of the current controller are the current reference and the rotor speed, while its output is the reference voltage. The reference voltage will be applied to a space vector pulse width modulation (SVPWM) unit. The outputs of the PI controllers are limited and have anti-reset windup. Compensation methods can be used to improve the performance at low speeds.

\section{Simulation Results}

Proposed drive system block diagram is presented in Fig. 5, When the carrier frequency of SVPWM is $2000 \mathrm{~Hz}$, the DC bus voltage is $200 \mathrm{~V}$, and the phase is switched to the next in every 60 electrical degrees. The operation duration of each power electronic part is 120 electrical degrees. When the parameters of speed regulator are set as $K_{p}=0.5, K_{i}=100$; the q-axis current regulator is set as $K_{p}=\log (9) \times$ cc_bandwidth $\times L_{q}, K_{i}=K_{p} \times\left(R_{s} / L_{q}\right)$; the d-axis current controller is set as $K_{p}=\log (9) \times c c_{-}$bandwidth $\times L_{d}$, $K_{i}=K_{p} \times\left(R_{s} / L_{d}\right)$, where cc_bandwidth is current controller bandwidth and is set to 400 . Motor $a, b, c$ currents, rotor speed, electromagnetic torque and rotor angle of the Axial Flux PMSM are shown in Fig. 6. It can be seen that the simulations agree with common operational characteristics, proving the validity of the presented model.

The simulation reference speed is set as $190 \mathrm{Rad} / \mathrm{Sec}$, the simulation step is $0.00001 \mathrm{Sec}$, and the simulation time is 0.5 $\mathrm{sec}$. At $t=0 \mathrm{Sec}$, the motor starts up with no-load; at $t=0.1 \mathrm{Sec}$ $\mathrm{s}$, a load torque of $2 \mathrm{N.m}$ is applied. From the simulations, it can be seen that the startup speed of motor is fast and is able to follow the reference speed. With load torque, the fluctuation of rotary speed waveform is very small. At simulation time $t=0.2 \mathrm{Sec}$ load torque is changed to zero and we study the un-loading dynamics of the drive system. After $t=0.1 \mathrm{Sec}$ at $t=0.3 \mathrm{Sec}$ speed reference is changed to -190 $\mathrm{Rad} / \mathrm{Sec}$ and drive system after some oscillations that lasts for $0.1 \mathrm{Sec}$ reaches to its steady state condition on $-190 \mathrm{Rad} / \mathrm{Sec}$. Parameters of the Axial Flux PMSM are used in the simulation listed in Appendix A.

Figure 7 shows the simulated waveforms of $d-q$ axis stator currents. When $t=0.1 \mathrm{Sec}$, a torque of $2 \mathrm{N.m}$ is applied from no-load and at $t=0.2 \mathrm{Sec}$ drive is unloaded. It can be observed that the $q$-axis current is directly proportional to the torque, while the $d$-axis current is nearly zero. It can be concluded that the three-phase stator currents have well been decoupled.

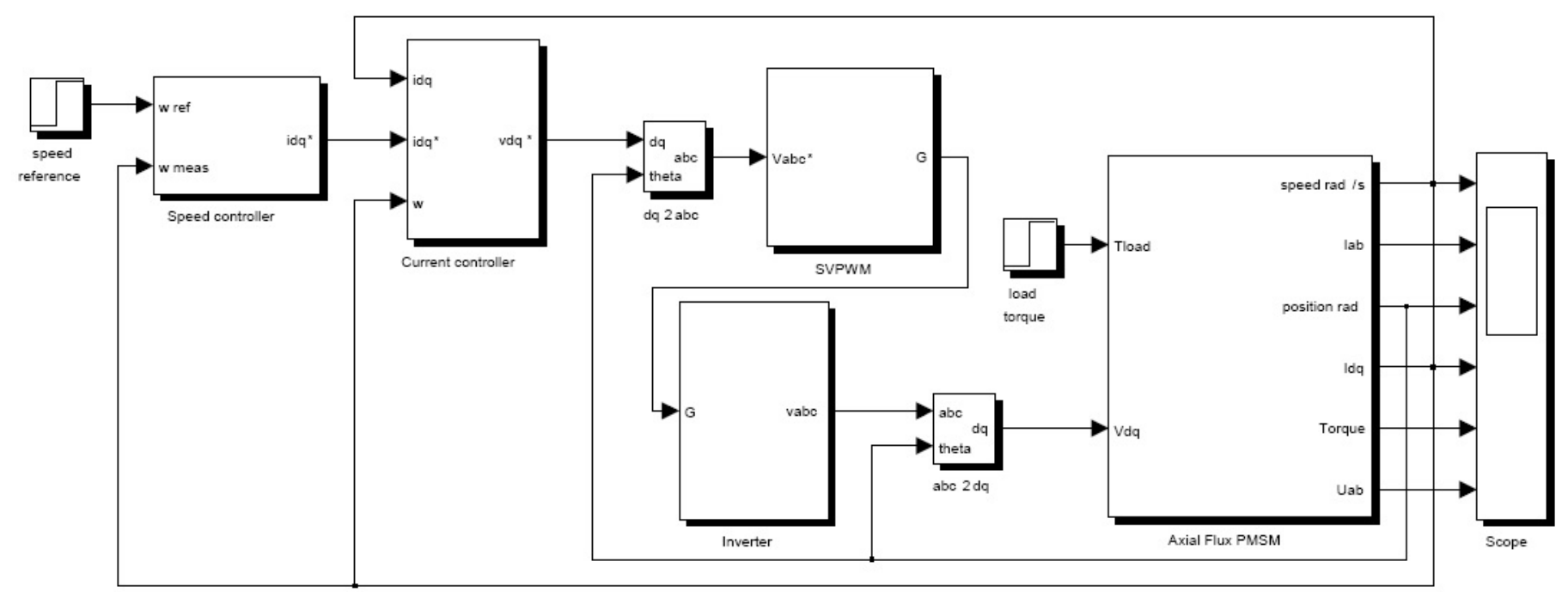

Figure 5. Drive system SIMULINK model 
With a reference speed of $190 \mathrm{Rad} / \mathrm{Sec}$, phase voltage waveforms are shown in Fig. 7. The section transform of the voltage vector is shown in Fig. 8. It can be seen that the voltage vector rotates anticlockwise in proper order at steady state condition, (i.e. 1(POO), 2(PPO), 3(OPO), 4(OPP), 5(OOP), 6(POP) for positive speed and vice-versa). Fig. 8 accords with Table 2. From the rotor speed response curve, it is observed that after starting-up, the motor accelerates to a stable value quickly. And after loading and un-loading conditions in a very small time oscillations damp to zero. Like other variable speed drives in this study we observe that speed fluctuations are relatively larger than those in starting condition. Similarly, the electromagnetic torque and the three phase currents maintain at the steady values with small fluctuation shortly.

\section{CONCLUSION}

Comparing with the SPWM, the main advantage of SVPWM is that it has a $15 \%$ higher utilization ratio of voltage. In this study SVPWM is achieved by implementing the zero voltage space vectors in the phase modulation wave of SPWM. SPWM is easier to be realized in hardware circuit, while SVPWM is more suitable for digital control system. This paper presents the MATLAB/SIMULINK-based simulation model by adopting the classical double closed loops of speed and current and vector control method. The simulation results reveal that the waveforms are in accord with theoretical analysis, the system can operate stably with fairly good steady-state and dynamic characteristics provide sound bases for developing both software and hardware to realize Axial Flux PMSM machines.
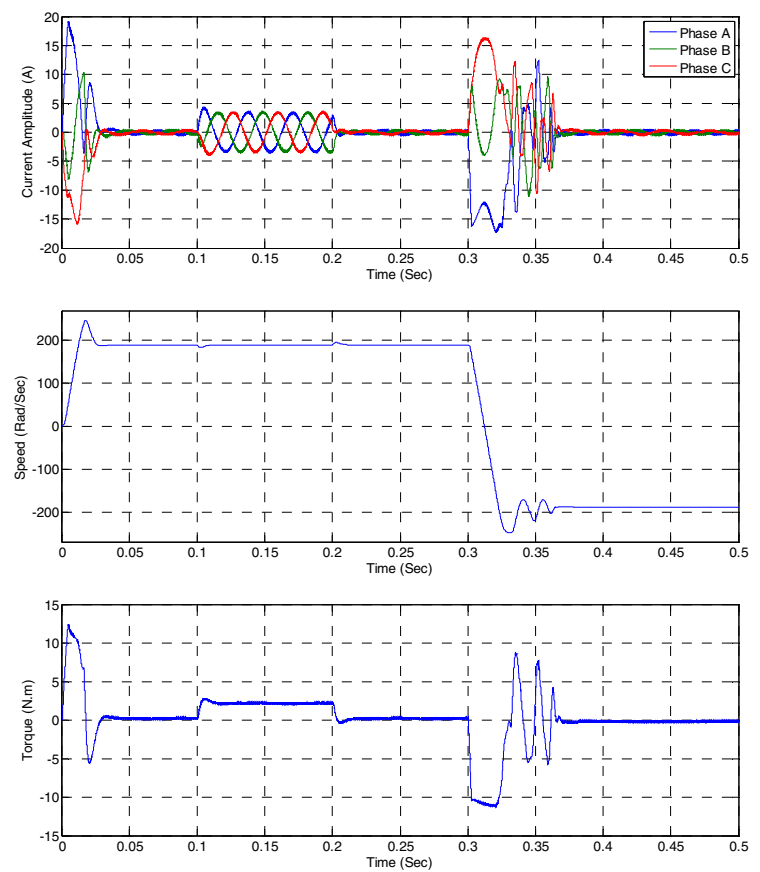

Figure 6. $a, b, c$ currents, speed, torque, position
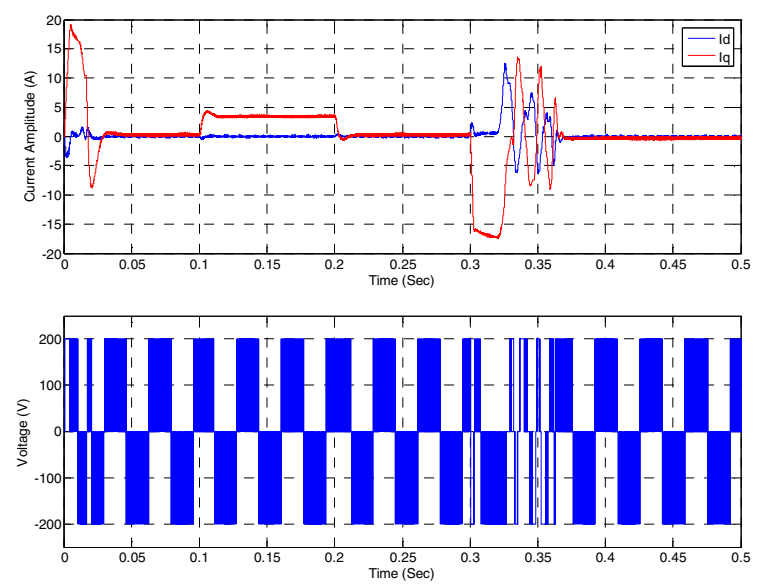

Figure 7. $d-q$ currents, phase A voltage

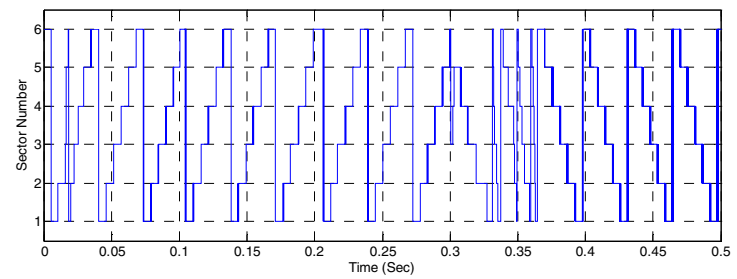

Figure 8. Sector transform of voltage vector

APPENDIX A

The following motor parameters are used for SIMULINK simulation:

TABLE IV

DATA USED IN SiMULATION

\begin{tabular}{|l|l|l|}
\hline \hline Parameter & Symbol & Value \\
\hline Stator winding self inductance & $L_{s}$ & $32 \mathrm{mH}$ \\
Stator winding resistance & $R_{s}$ & $5 \Omega$ \\
Back EMF constant & $K_{e}$ & $0.215 \mathrm{Vs} / \mathrm{rad}$ \\
Damping & $B$ & $0.001 \mathrm{Ns} / \mathrm{rad}$ \\
Number of Pole-Pairs & $P$ & 2 \\
Rotor Inertia & $J$ & $0.6 \times 10^{-3} \mathrm{Kg} \cdot \mathrm{m}^{2}$ \\
Nominal speed & $\omega_{n}$ & $190 \mathrm{rad} / \mathrm{s}$ \\
Nominal Torque & $T_{n}$ & $2 \mathrm{Nm}$ \\
Drive current limit & $I_{\max }$ & $16 \mathrm{~A}$ \\
Drive voltage limit & $V_{\max }$ & $200 \mathrm{~V}$ \\
\hline
\end{tabular}

\section{REFERENCES}

[1] S. Ogasawara, M. Nishimura, H. Akagi, A. Nabae, and Y. Nakanishi, "A high performance AC servo system with permanent magnet synchronous motors," IEEE Transactions on Industrial Electronics, vol. 33, no. 1, pp. 87-91, 1986.

[2] Zheng-Guang Wang, Jian-Xun Jin, You-Guang Guo, and Jian-Guo Zhu "SVPWM Techniques and Applications in HTS PMSM Machines" Control journal of electronic science and technology of china, VOL. 6, NO. 2, JUNE 2008

[3] B. T. Ooi, J. C. Salmon, J. W. Dixon, and A. B. Kulkarni, "A three phase controlled-current PWM converter with leading power factor," IEEE Transactions on Ind. Application, vol. 23, no. 1, pp. 78-84, 1987

[4] J. W. Dixon and B. T. Ooi, "Indirect current control of a unity power factor sinusoidal current boost type three-phase rectifier," IEEE Transactions on Ind. Electron, vol. 35, no. 4, pp. 508-515, Nov. 1988.

[5] P. Pillay and R. Krishnan, "Modeling of permanent magnet motor drives," IEEE Trans. Industrial Electronics, vol 35 , no. 4 , Nov. 1988, pp.537-541. 
[6] S. M. Hosseini, M. Agha-Mirsalim, and M. Mirzaei, "Design, prototyping, and analysis of low cost axial-flux coreless permanentmagnet generator," IEEE Trans. Magn., vol. 44, no. 1, pp. 75-80, Jan. 2008.

[7] J. A. Tapia, D. González, R. Wallace, and A. Valenzuela, "Axial flux surface mounted PM machine with field weakening capability," in Int.Conf. Electrical Machines, ICEM'2004, Krakow, Poland.

[8] R. Krishnan and A. J. Beutler, "Performance and design of an axial field permanent magnet synchronous motor servo drive," in Proc. IEEE IAS Annu. Meeting, pp. 634-640, 1985.

[9] D. G. Holmes and T. A. Lipo, Pulse Width Modulation for Power Converters-Principle and Practice, IEEE Press/Wiley-Interscience, New York, 2003.

[10] M. H. Rashid, Power Electronics Handbook, Academic Press, New York, 2001.

[11] Lennart Harnefors, Hans-Peter Nee, "Model-Based Current Control of AC Machines Using the Internal Model Control Method" IEEE transaction on industry application, VOL. 34, NO. 1, Jan / Feb 1998 